Gregor Rohmann, Tanzwut. Kosmos, Kirche und Mensch in der Bedeutungsgeschichte eines mittelalterlichen Krankheitskonzepts

Göttingen : Vandenhoeck \& Ruprecht (Historische Semantik, 19), 2013, 712 p., $99,99 €$

Pierre Monnet

\title{
CpenEdition
}

Journals

Édition électronique

URL : http://journals.openedition.org/ifha/8131

DOI : $10.4000 /$ ifha. 8131

ISSN : 2198-8943

Éditeur

IFRA - Institut franco-allemand (sciences historiques et sociales)

Référence électronique

Pierre Monnet, « Gregor Rohmann, Tanzwut. Kosmos, Kirche und Mensch in der Bedeutungsgeschichte eines mittelalterlichen Krankheitskonzepts », Revue de I'IFHA [En ligne], Date de recension, mis en ligne le 14 avril 2015, consulté le 22 septembre 2020. URL : http://journals.openedition.org/ifha/8131 ; DOI : https://doi.org/10.4000/ifha.8131

Ce document a été généré automatiquement le 22 septembre 2020.

(CIFHA 


\section{Gregor Rohmann, Tanzwut. Kosmos, Kirche und Mensch in der Bedeutungsgeschichte eines mittelalterlichen Krankheitskonzepts}

Göttingen : Vandenhoeck \& Ruprecht (Historische Semantik, 19), 2013, 712 p., $99,99 €$

Pierre Monnet

Est-il bien raisonnable d'écrire plus de 700 pages sur la danse de Saint-Guy au Moyen Âge? On le sait, la maladie auto-immune appelée savamment chorée de Sydenham, du nom du médecin anglais réputé pour être l'un des pères de la pathologie moderne, n'a été décrite que dans les années 1680. Mais toute maladie a une histoire avant sa description et ses traitements modernes. Tel est le cas de l'épilepsie de la danse dite de Saint-Guy appelée telle vers le IXe siècle (chorea sancti viti) après des guérisons miraculeuses observées lors du transfert des reliques de saint Guy (le saint sauveur de la vie du fils de Dioclétien, martyrisé en 304 et à ce titre incorporé parmi les 14 saints auxiliaires) de Saint-Denis (où elles étaient arrivées en 756) translatées sous forme de présent à l'abbaye de Corvey en Saxe en 836.

Le sous-titre du livre imposant et fascinant de Gregor Rohmann livre déjà la réponse à la question initiale et fait mieux comprendre pourquoi ce symptôme peut être «bon à penser " pour l'historien : il s'agit en effet de comprendre comment les interprétations historiquement situées d'une maladie aussi frappante (l'agitation incontrôlée du corps, tant individuelle que collective, par exemple sous la forme plus tardive des groupes de convulsionnaires) permettent de relire les relations qui se nouent au Moyen Âge entre le religieux, le clérical, le milieu de vie et une définition de l'homme. Il ne faut pas moins de 38 chapitres à l'auteur pour cerner de manière époustouflante, aux sources d'une érudition rare, d'une documentation exhaustive et variée et d'une grille d'interprétation croisant médecine, hagiographie, chronistique, iconographie, anthropologie, les phénomènes culturels, sociaux, religieux liés à ce que la société 
médiévale a conçu certes comme un désordre du corps mais aussi comme une expérience de la frontière avec le sacré, de la possession. Ce livre installe donc véritablement la danse de Saint-Guy en lieu anthropologique global, en sujet exemplaire d'une histoire culturelle à cent coudées des études folkloriques auxquelles elle avait jusqu'à présent donné lieu.

L'analyse suit un fil heuristique à la fois astucieux et ambitieux, que résume parfaitement une question capitale posée page 65 "Comment la culture vient au corps? » et qui consiste donc à regarder la danse de Saint-Guy comme un réservoir de signes et de ressources pour comprendre, à travers les approches sémiotiques, étymologiques, pathologiques, religieuses, rituelles, sacrées, cosmologiques, hagiographiques, comment la perception, la dénomination, la condamnation, la fascination, la narration, la rétroprojection, l'invention du phénomène dévoilent des réflexes, des discours, des schèmes profonds de la pensée et de la société médiévales. Cela ne va pas sans déblayer un amas de couches interprétatives, elles-mêmes historiquement bonnes à penser, qui ont rangé la danse de Saint-Guy parmi diverses catégories telles que les hystéries, manies, maladies, folies, possessions/dépossessions de soi, surgissements du diable ou de dieux anciens... Gregor Rohmann parvient en permanence à construire en déconstruisant pour retrouver des logiques matricielles de la société médiévale : la difficile et longue confrontation avec des religions et des cosmogonies antiques recouvertes mais pas complètement éliminées par le christianisme ; la complexe et ambivalente relation de l'Église chrétienne avec le corps en général, et le corps désordonné en particulier; la concentration des phénomènes observés, individuels ou collectifs, dans un espace européen mitoyen entre France et Allemagne, entre Meuse, Moselle et Rhin, c'est-à-dire dans une zone de contacts de longue durée entre cultures et traditions contradictoires et complémentaires tout ensemble ; la mutation, avec la Réforme grégorienne, d'un schème structural de l'Église vue jusqu'alors comme un cercle puis désormais comme une maison, réordonnant dès lors les valeurs liées aux pratiques culturelles et corporelles «encerclées » (telle la danse).

Bref, comme on peut aisément le voir, cette étude magistrale et foisonnante n'est pas avant tout un livre sur la danse, mais tout simplement une plongée dans les tréfonds de la culture vive, colorée, changeante d'un long Moyen Âge qui nous parle encore.

\section{INDEX}

Index chronologique : Moyen Âge

Thèmes : Histoire de la culture, Histoire des mentalités, Histoire des sciences 
AUTEUR

PIERRE MONNET

EHESS, IFHA 